http://dx.doi.org/10.5007/1982-5153.2015v8n1p153

\title{
O Caráter Dual do Termo Interdisciplinaridade na Literatura, nos Documentos Educacionais Oficiais e nos Professores de Química
}

(The Dual Character of the Term Interdisciplinarity in the Literature, in Official Educational Documents and in Chemistry Teachers)

\section{VALDIR PEDRO BERTI A CARMEN FERNANDEZ}

Universidade de São Paulo (vpberti@yahoo.com.br, carmen@iq.usp.br)

\begin{abstract}
Resumo. Interdisciplinaridade é um termo bastante mencionado no contexto educacional, embora as interpretações nem sempre sejam convergentes. Neste trabalho realiza-se um panorama sobre concepções de interdisciplinaridade na literatura e nos documentos oficiais brasileiros e faz-se um paralelo com as concepções expressas por professores pesquisadores universitários e professores de química da educação básica. Foram investigados dezesseis professores, seis dos quais atuaram também como consultores do MEC na elaboração dos documentos oficiais. Os dados se basearam em entrevistas semiestruturadas e, a partir das unidades de análise foram construídos mapas cognitivos. Os resultados revelam duas interpretações de interdisciplinaridade coexistentes: pelo professor e entre professores. A interdisciplinaridade pelo professor pressupõe que um professor de uma dada disciplina faça avanços em outras disciplinas. A interdisciplinaridade entre professores pressupõe um grupo de professores de distintas disciplinas trabalhando um mesmo tópico. Os dados apontam que a interdisciplinaridade convive com orientações diversas, o que pode estar dificultando sua implantação.

Abstract. Interdisciplinarity is a term often mentioned in the educational context, although the interpretations are not always convergent. In this paper it was carried out an overview of interdisciplinary concepts in literature and Brazilian official documents. It was also made a parallel with the views expressed by university researchers and chemistry teachers of basic education. Sixteen teachers were investigated, six of which also acted as MEC consultants in the preparation of official documents. The data were based on semi-structured interviews and from the analysis units cognitive maps were constructed. The results reveal two interpretations of coexisting interdisciplinarity: by the teacher and between teachers. Interdisciplinary by the teacher assumes that a chemistry teacher make advances in other disciplines. The interdisciplinary between teachers presupposes a group of teachers from different disciplines working the same subject. Data points out interdisciplinarity coexists with different orientations, which may be hindering its implementation.
\end{abstract}

Palavras-chave: interdisciplinaridade, concepção de professores, políticas públicas, mapas cognitivos

Keywords: interdisciplinarity, teachers' conceptions, official documents, cognitive maps

\section{Introdução}

Interdisciplinaridade é um termo que tem sido amplamente utilizado no contexto educacional (CZERNIAK, 2007; BERTI, 2007; COLL et al., 2013). Especialmente no contexto brasileiro a discussão tem sido enfatizada ultimamente desde que o Ministério da Educação (MEC) anunciou uma integração curricular por áreas do conhecimento no Ensino Médio brasileiro e, nessa mudança, as disciplinas de física, química e biologia seriam ministradas por um único professor sob a denominação de "ciências da natureza" (MOZENA, OESTERMANN, 2014). O principal objetivo do "redesenho curricular" seria a extinção das disciplinas e a oferta de um ensino integrado organizado por áreas, de maneira a sanar problemas de falta de professores especialistas e propiciar que os docentes trabalhem em apenas uma escola, ou seja, um ensino integrado com caráter 
mais interdisciplinar, já que um mesmo professor do Ensino Médio ficaria a cargo dos conteúdos de Física, Química e Biologia, por exemplo.

Recentemente ainda, em janeiro de 2012, foram promulgadas as novas Diretrizes Curriculares Nacionais do Ensino Médio, DCNEM (BRASIL, 2012). Nas DCNEM (2012) desaparecem os termos "competências" e "habilidades", e a "interdisciplinaridade" reaparece de maneira realmente institucionalizada. Nas DCNEM (1998) a interdisciplinaridade era compreendida como um "princípio pedagógico", agora, nas DCNEM (2012), é fundamentada como "base da organização do Ensino Médio" (MOZENA, OESTERMANN, 2014).

Assim, a interdisciplinaridade continua no centro das atenções do currículo brasileiro e é considerada como um modo de superar a organização curricular disciplinar que permanece sendo a organização dominante em nossas escolas (LOPES, MACEDO, 2002; LOPES, 2007) e a abordagem disciplinar tem sido considerada incapaz de responder às tendências educacionais atuais. Em contrapartida, apesar de necessária e importante, a interdisciplinaridade na sala de aula, está conjugada a uma série de problemas e dificuldades que se iniciam na falta de um consenso sobre a sua natureza epistemológica (MOZENA, OESTERMANN, 2014).

Essas autoras defendem a interdisciplinaridade em momentos específicos do fazer docente, pois, existem problemas estruturais no Ensino Médio que inviabilizam propostas mais integradoras, como a formação docente disciplinar e condições de trabalho da escola para promover a integração das áreas. Além disso, há um consenso na literatura de que a interdisciplinaridade pressupõe a existência e permanência das disciplinas (CZERNIAK, 2007; BERTI, 2007; RICARDO, ZYLBERSZTAJN, 2008; COLL et al., 2013; MOZENA, OESTERMANN, 2014).

Ricardo e Zylbersztajn (2008) defendem também que, os elaboradores dos Parâmetros Curriculares Nacionais para o Ensino Médio, PCNEM e PCN+ (BRASIL, 1998; 2002) tiveram como documentos orientadores disponibilizados pelo MEC: a Lei de Diretrizes e Bases da Educação Nacional, LDB 9394/96 (BRASIL, 1996) e as Diretrizes Curriculares Nacionais para o Ensino Médio, DCNEM (BRASIL, 1998). Entre esses documentos, a ideia de competências, interdisciplinaridade e contextualização está presente de forma mais explícita nas DCNEM. Contudo, segundo os autores, o que de fato prevaleceu na elaboração dos documentos orientadores para o Ensino Médio - PCNEM (BRASIL, 1999) e PCN+ (BRASIL, 2002), foram as 
concepções dos elaboradores, as quais emanaram muito mais de suas práticas e experiências.

Os autores deixam claro que a interdisciplinaridade e contextualização são propostas discutidas de forma intensa na literatura brasileira, muito antes mesmo da própria LDB de 1996. Porém, a falta de clareza dos documentos orientadores levou a uma má compreensão nos meios educacionais. Nestes, os trabalhos são orientados por projetos temáticos em oposição às disciplinas. Essa falta de entendimento traz impedimentos de natureza epistemológica e procedimentais; sendo, portanto muito difíceis de serem implementados na prática escolar, devido às condições de trabalho e estruturas das escolas.

Para esses autores ainda, as ideias defendidas nas escolas não têm respaldo nos documentos oficiais, uma vez que os elaboradores dos PCNEM e PCN+ defendem que interdisciplinaridade não pode ser entendida como um retorno a uma totalidade dos saberes. A ideia de interdisciplinaridade não é a de se opor às disciplinas, mas de vislumbrar competências e habilidades, as quais para serem construídas necessitam da cooperação das disciplinas.

De acordo com Mozena e Ostermann (2014) há por parte do Ministério da Educação a intenção explícita de implementar um currículo integrado, pressupondo a superação das disciplinas. Esse esforço pode ser observado, por exemplo, com o Exame Nacional do Ensino Médio (ENEM), 1998, o qual se constitui por áreas do conhecimento; o Programa Ensino Médio Inovador (ProEMI, 2013), com os Projetos de Redesenho Curricular (PRC), incentivando a pesquisa por área do conhecimento, e de certa forma, a pressão exercida para que todas Universidades Federais aceitem o ENEM em seus processos seletivos.

Pode-se notar, entretanto que, embora frequentemente utilizado, o termo interdisciplinaridade não possui uma definição clara e a falha na compreensão do termo, além da falta de condições de trabalho da escola, podem estar na base das dificuldades da implementação de abordagens interdisciplinares. Nesse sentido, objetivamos neste trabalho traçar um panorama das concepções de interdisciplinaridade que aparecem na literatura da área, as que embasam as propostas oficiais brasileiras para o Ensino Médio e traçar um paralelo com aquelas que têm sido interpretadas pelos agentes escolares no contexto do ensino de química. 


\section{Interdisciplinaridade na literatura}

Diferentes visões de interdisciplinaridade podem ser identificadas na literatura e nosso enfoque se concentrará entre os anos compreendidos entre 1970 até o momento atual, pois julgamos que nesse período a interdisciplinaridade teve forte expressão na pesquisa e no ensino.

Japiassu publicou um dos trabalhos pioneiros sobre a interdisciplinaridade no Brasil, no ano de 1976. Ele considera que a interdisciplinaridade é um método de pesquisa e de ensino suscetível de fazer duas ou mais disciplinas interagirem. Essa interação pode ser uma comunicação de ideias, a interação dos conceitos, da epistemologia, terminologia, metodologia, procedimentos, dados e organização da pesquisa. Ele expressou sua opinião sobre a interdisciplinaridade como:

A interdisciplinaridade caracteriza-se pela magnitude das mudanças entre os especialistas e pelo grau de interação entre as disciplinas, no âmbito de um projeto de pesquisa. (JAPIASSU, 1976, p. 74)

Piaget (1978) defende que a aproximação das disciplinas está relacionada ao aspecto epistemológico, pois algumas delas têm formas muito próximas de atuar na consecução do conhecimento, como por exemplo, na Física e na Química, na Biologia e Físico-Química. De acordo com esse autor, no momento em que se procura entender os fenômenos e suas leis, ao invés de apenas descrevê-los ou memorizá-los algoritmicamente, inevitavelmente, ocorre a superação das fronteiras disciplinares, pois elas têm formas muito semelhantes de se constituírem:

[...] Ora, a partir do momento em que ultrapassamos o observável para iniciarmos a busca dessas coordenações necessárias, segue-se que, mais cedo ou mais tarde, ultrapassamos as fronteiras da ciência em causa e penetramos no domínio das ciências vizinhas. (PIAGET, 2006, p. 59)

A epistemologia construtivista de Piaget busca desvelar o processo de construção do conhecimento, apontando para a unidade das ciências. Uma unidade que, ao que parece, pode ser construída pela apropriação do próprio sujeito. Tais pensamentos são também comuns a Jantasch e Bianchetti, ao afirmarem que:

À ideia de que somente é possível ser interdisciplinar em grupo, contrapomos a de que a sós também é possível. Um grupo pode ser mais homogêneo e superficial que o indivíduo que busca recursos de várias ciências para explicar determinado processo, são bons exemplos as obras de Marx, Piaget, Gramsci, Weber, Florestan Fernandes e outros. (JANTSCH, BIANCHETTI, 1995, p. 23-24)

Ainda que de forma mais empírica, encontramos ideias semelhantes na Teoria Geral dos Sistemas de Bertalanffy $(1977,2012)$. Este autor reporta uma teoria capaz de ser aplicada nas várias áreas do conhecimento na busca da integralidade. Bertalanffy 
defendia uma formação de cientistas com capacidades mais generalizadoras, conhecedores de princípios interdisciplinares:

\begin{abstract}
Muitas vezes ouvimos dizer que um único homem não pode mais abranger um campo bastante amplo e que há demasiada especialização estreita. Precisamos de uma abordagem mais simples, mais unificada dos problemas científicos, precisamos de homens que pratiquem a ciência e não de uma ciência particular, numa palavra precisamos de generalistas científicos. (BERTALANFFY, 1977, p. 77)
\end{abstract}

$\mathrm{Na}$ busca dessa unidade aparecem também as ideias do filósofo humanista Gusdorf (1984, 2006), que propôs um projeto em que a pesquisa teórica tivesse por base a unidade nas ciências humanas. Essa unidade seria considerada como básica para definir o domínio de uma pesquisa fundamentalmente integradora. Esse propósito integrador poderia trazer contribuições favoráveis para o futuro de cada ciência em particular, pois as questões a serem investigadas contariam com a colaboração de todas as disciplinas, ou de algumas, o que certamente ampliaria o campo de compreensão sobre o objeto de estudo.

Segundo Ivani Fazenda, na década de 70 do século passado, as propostas interdisciplinares traziam um sentido de unidade, uma vez que buscavam a convergência entre o papel humanista do conhecimento e da ciência. "A intenção desse projeto seria orientar as ciências humanas para a convergência de trabalhar a unidade humana" (FAZENDA, 1994, p. 19). Ideias que, segundo ela, trouxeram alguns equívocos nessa época, quando se começou a pesquisar a interdisciplinaridade, em que se pressupunham acabar com as disciplinas em nome de uma pseudointegração (FAZENDA, 1993, 1994, 2005).

Para Japiassu (1976) o interdisciplinar não deve pretender ser um campo unitário do conhecimento, ou uma unidade construída pela adição das especialidades e, nem tampouco, por uma síntese dos saberes específicos. O espaço interdisciplinar deve ser construído na superação das fronteiras disciplinares. A pesquisa interdisciplinar começa a se evidenciar, segundo ele, à medida que seus participantes evoluem para uma pesquisa com uma produção de uma linguagem comum. Pontos essencialmente defendidos por Gusdorf (1984), ao afirmar que trabalhos interdisciplinares autênticos devem evoluir para a construção de uma metodologia, procedimentos e linguagem comuns, sendo a condição para o surgimento de um saber novo, uma autêntica produção interdisciplinar. Assim, para esse autor, imaginar que a interdisciplinaridade possa ser alcançada pelo especialista com tributo do seu trabalho é um equívoco, pois se a 
preocupação da unidade humana do saber não é considerada no ponto de partida da investigação, certamente não se encontrará no ponto de chegada.

Para Santomé (1998) a interdisciplinaridade se coloca como uma metodologia, que não depende somente das disciplinas, pois está associada a certos "traços da personalidade", como: flexibilidade, confiança, paciência, capacidade de adaptação, aceitação de riscos e capacidade de aprender a agir na diversidade. Uma proposta de trabalho que está diretamente relacionada ao nível de conhecimento, flexibilidade e convergência dos participantes na sua consecução. Características muito comuns ao pensamento de Fazenda $(1993,1994)$, ao propor a interdisciplinaridade como uma relação de reciprocidade, de mutualidade, ou melhor, um regime de co-propriedade que possibilita o diálogo entre os interessados. Neste sentido, pode-se dizer que a interdisciplinaridade depende basicamente de uma atitude, traduzida entre o diálogo dos interessados e co-responsáveis pelo processo interdisciplinar. Uma atitude que se constrói na prática, superando a dicotomia (teoria e prática), algo que pode ser observado na pesquisa. Esse diálogo interdisciplinar, entretanto, deve ser feito com a presença das disciplinas. Suas críticas não são direcionadas às disciplinas, mas aos recortes excessivos nos conteúdos, os quais impossibilitam a compreensão na sua essencialidade.

Machado (2001, 2002), por sua vez, considera quatro dimensões nas propostas integradas, a saber: multidisciplinaridade, interdisciplinaridade, intradisciplinaridade e transdisciplinaridade.

Multidisciplinaridade: os objetivos próprios de cada disciplina são preservados, conservando-se sua autonomia, seus objetos, sendo tênues as articulações entre as mesmas.

Interdisciplinaridade: busca-se o estabelecimento de uma intercomunicação efetiva entre as disciplinas, por meio do enriquecimento das relações entre elas. Almeja-se, a composição de um objeto comum, por meio dos objetos particulares de cada uma das disciplinas participantes.

Intradisciplinaridade: as progressivas particularizações do objeto de uma disciplina dão origem a uma ou mais subdisciplinas, que não chegam verdadeiramente a deter uma autonomia, nem no que se refere ao método nem quanto ao objeto.

Transdisciplinaridade: a constituição de novo objeto dá-se em movimento ascendente, de generalização (MACHADO, 2002, p. 135-136).

No eixo multi/interdisciplinar, as unidades disciplinares são conservadas. Ocorre um avanço na interação, em que as disciplinas se debruçam sobre um problema comum (objeto), convidando as demais a contribuírem para aumentar o sentido daquilo que se propõem estudar. A interdisciplinaridade pressupõe um aumento das relações entre as disciplinas, pois não é razoável que as disciplinas trabalhem sem se relacionar, ou com 
fracas interações. Então, o que se busca é esse aumento de interação; intenciona-se uma composição de um objeto comum, por meio das contribuições disciplinares, com um enriquecimento mútuo dos participantes. No eixo intra/transdisciplinar, a característica básica das relações estabelecidas é a verticalidade. De um lado, ocorre o afunilamento no sentido da especificidade da disciplina; no outro, o olhar se dá numa perspectiva maior, não se detendo exclusivamente no objeto das disciplinas. $\mathrm{O}$ espectro se amplia para questões como mapeamento genético, ética educacional, antropologia etc.; questões relacionadas com a pessoalidade.

Zabala (1998, 2002), entende a interdisciplinaridade como uma cooperação entre diversas disciplinas, que se traduz em um mesmo conjunto de conceitos e métodos de investigação. Assim:

\begin{abstract}
A interdisciplinaridade é a interação de duas ou mais disciplinas, que pode ir desde a simples comunicação de ideias até a integração recíproca dos contextos fundamentais e da teoria do conhecimento, da metodologia e dos dados de pesquisa. Estas interações podem implicar transferências de leis de uma disciplina para outra e, inclusive, em alguns casos dão lugar a um novo corpo disciplinar, como a bioquímica ou a psicolinguística. Podemos encontrar esta concepção na configuração das áreas de Ciências Sociais e Ciências Experimentais no Ensino Médio e da área de Conhecimento do meio no ensino fundamental. (ZABALA, 2002, p. 18)
\end{abstract}

Assim, observamos na literatura duas concepções emergentes de propostas interdisciplinares, interações que podem ser feitas pelo sujeito, ou entre os sujeitos na busca de uma maior compreensão da realidade. Tais concepções, porém, longe de se apresentarem como uma evolução cronológica conviveram e convivem em tempos comuns.

No intuito de investigar se essas concepções de interdisciplinaridade se refletem nos documentos educacionais oficiais brasileiros e nos professores de química em atuação e em formação, foram investigados os documentos das políticas públicas brasileiras e foram feitas entrevistas com diversos professores como será descrito no item seguinte.

\title{
Aspectos metodológicos da pesquisa
}

A fim de revelar se as duas orientações sobre interdisciplinaridade emergentes da literatura analisada eram reproduzidas nos documentos oficiais e refletidas na atuação dos professores de química, foi realizada primeiramente uma análise minuciosa da literatura já apresentada no item anterior e, na sequência, dos documentos oficiais brasileiros. A sequência da análise, tanto da literatura, quanto dos documentos oficiais 
não se deu de forma linear, pois foi se constituindo a partir da necessidade de maior conhecimento sobre a temática pela referência nos documentos orientadores descritos abaixo e pela própria entrevista com alguns pesquisadores/consultores do MEC, os quais são professores universitários de química, física e de educação e, ainda, autores consagrados no estudo da interdisciplinaridade. Da literatura, os autores estudados e já apresentados incluem Jean Piaget, Georges Gusdorf, Ludwig von Bertalanffy, Jantasch e Bianchetti, Hilton Japiassu, Jurjo Torres Santomé, Ivani Fazenda, Nilson Machado e Antoni Zabala.

Os documentos oficiais de ensino investigados incluem: Lei de Diretrizes e Bases da Educação Brasileira - Lei 9394/1996 (BRASIL, 1996); Parâmetros Curriculares Nacionais para o Ensino Médio (BRASIL, 1999, 2002); Orientações Curriculares Nacionais para o Ensino Médio (BRASIL, 2004, 2006).

Os textos da literatura foram extensivamente lidos e tratados utilizando a análise de conteúdo (BARDIN, 2003). Dessa análise dos dados emergiram as duas categorias propostas: interdisciplinaridade pelo professor e interdisciplinaridade entre professores. A análise de conteúdo também foi utilizada para analisar os documentos oficiais e as entrevistas. Particularmente para as entrevistas foram construídos mapas cognitivos que serão descritos mais adiante.

Foram realizadas dezesseis entrevistas semiestruturadas com professores, oito deles são professores universitários e pesquisadores acadêmicos em Ensino de Química, Ensino de Física ou/e Educação, seis desses pesquisadores foram consultores do MEC na elaboração dos documentos oficiais: PCNEM, PCN+ e OCNEM. Oito professores de Química do Ensino Médio foram também entrevistados, três deles matriculados na época em um programa de pós-graduação em Ensino de Ciências. As entrevistas tiveram uma duração média de uma hora e foram totalmente transcritas. A análise das entrevistas foi feita através da leitura extensiva, seleção de unidades de análise e construção de mapas cognitivos (LLINARES, 1992).

\section{Mapas Cognitivos}

Os mapas cognitivos podem ser descritos como um instrumento de análise qualitativa, que representa a imagem mental de uma pessoa no que diz respeito a um objeto ou situação (MELLADO, SILVA, RUIZ, 2004; RUIZ et al., 2005) e se fundamentam na Teoria de Constructos Pessoais (EDEN, 1988; ARAÚJO, RIEDG, 
2003). Mapas cognitivos relacionam unidades de informação de uma forma parcialmente hierárquica, relacionando sistematicamente tais unidades.

O mapa cognitivo tende a uma estrutura mais psicológica, formando uma representação idiossincrática da pessoa (LLINARES, 1992; RUIZ et al., 2005). Trata-se de um instrumento útil para auxiliar na elaboração e estruturação de pesquisas qualitativas. Seu uso tem sido bastante intenso, na psicologia e no ensino, pois nestes contextos são usados como sistemas para explicitar descrições da "imagem mental" de uma pessoa a respeito de suas concepções. Assim, esses mapas têm ajudado na construção das representações, e de alguma forma, sistematizado as ideias principais dos entrevistados (LLINARES, 1992; BERMEJO, GONZÁLEZ, MELLADO, 2004; MELLADO, SILVA, RUIZ, 2004; RUIZ et al., 2005).

Assim, um mapa cognitivo assume a forma de uma rede de frases, "unidades de análise" ligadas por conectores, na qual, a frase captura e reflete diretamente a maneira como um indivíduo expressa uma ideia. Para Llinares:

[...] os mapas cognitivos são um modo de organizar os dados que se possui, portanto uma forma de facilitar as reflexões que podem levar à generalização de uma teoria que explique os dados obtidos. (LLINARES, 1992, p. 77)

A elaboração dos mapas cognitivos não segue uma ordem rígida; sendo impossível estabelecer regras para a sua execução, pois não se trata de uma ciência exata, mas de uma forma parcialmente hierarquizada de se dispor unidades de informação, permitindo uma visão global e não fragmentada das concepções dos entrevistados (BERMEJO, GONZALEZ, MELLADO, 2004; MELLADO, SILVA, RUIZ, 2004; 2005). Com intuito de sinalizar algumas etapas, relacionamos abaixo diretrizes de aspectos gerais para a sua elaboração, tendo-nos baseado nos trabalhos de Eden (1988) e Llinares (1992), basicamente são: decompor o relato em sentenças que irão constituir as unidades de análise, as quais constituem os conteúdos essenciais; identificar as relações do texto que podem caracterizar os níveis de microestrutura textual em que estão presentes as proposições individuais e algumas de suas relações, e o de macroestrutura, em que se caracteriza o texto como um todo; manter nos conceitos a linguagem usada pelo entrevistado, ao máximo; fazer, quando necessário, pequenas modificações, sem perder a propriedade da fala do entrevistado.

Para construir um mapa cognitivo dos professores a partir das entrevistas, "unidades de análise" foram selecionadas e organizadas de modo a apresentar uma visão 
global dos professores entrevistados. Os mapas foram enviados para os entrevistados para concordância.

De posse das análises dos dados, as concepções de interdisciplinaridade pelo e/ou entre professores foram sistematizadas em tabelas para fornecer um panorama de como essas orientações têm sido utilizadas pelos diferentes atores investigados.

\section{Resultados e discussão}

\section{A interdisciplinaridade na literatura}

Examinou-se na literatura o significado da interdisciplinaridade para os autores mencionados. A partir dessa análise, duas concepções de interdisciplinaridade, que diferem epistemologicamente, puderam ser identificadas. Nomeamos essas concepções emergentes como interdisciplinaridade entre os professores e pelo professor e as mesmas são caracterizadas como se segue:

i) Interdisciplinaridade entre os professores: considera que a abordagem interdisciplinar deve ser construída em trabalho conjunto de professores de disciplinas distintas.

ii) Interdisciplinaridade pelo professor: considera que a abordagem interdisciplinar deve ser desenvolvida por cada professor, e admite a necessidade do conhecimento de disciplinas distintas do conteúdo da especialidade do professor.

As concepções predominantes dos autores investigados foram assim classificadas nessas categorias, e os resultados estão apresentados na Tabela 1. Estas duas categorias - que surgiram a partir da análise das concepções dos autores investigados na literatura foram usadas para classificar as abordagens de interdisciplinaridade expressas pelos professores de química e aquelas que norteiam os documentos oficiais de ensino. 
Tabela 1 - Concepções de Interdisciplinaridade identificadas nos autores investigados.

\begin{tabular}{c|c|c}
\hline \multirow{2}{*}{ Autores } & \multicolumn{2}{c}{$\begin{array}{c}\text { Concepções Epistemológicas } \\
\text { de Interdisciplinaridade }\end{array}$} \\
\cline { 2 - 3 } & $\begin{array}{c}\text { entre } \\
\text { professores }\end{array}$ & $\begin{array}{c}\text { pelo } \\
\text { professor }\end{array}$ \\
\hline Jean Piaget & & $\mathrm{X}$ \\
\hline Jantasch e Bianchetti & & $\mathrm{X}$ \\
\hline Ludwig von Bertalanffy & & $\mathrm{X}$ \\
\hline Georges Gusdorf & $\mathrm{X}$ & \\
\hline Hilton Japiassu & $\mathrm{X}$ & \\
\hline Jurjo Torres Santomé & $\mathrm{X}$ & \\
\hline Ivani Fazenda & $\mathrm{X}$ & \\
\hline Nilson Machado & $\mathrm{X}$ & \\
\hline Antoni Zabala & $\mathrm{X}$ & \\
\hline
\end{tabular}

\section{A interdisciplinaridade como expressa nos documentos oficiais brasileiros de ensino}

O sistema escolar brasileiro segue uma estrutura básica com aplicação em todo o país, governado pela Lei de Diretrizes Brasileiras e Bases da Educação (LDB 9394/96), os Parâmetros Curriculares Nacionais para o Ensino Médio PCNEM (BRASIL, 1999) e PCN+ (BRASIL, 2002), e pelas Orientações Curriculares Nacionais do Ensino Médio (BRASIL, 2004, 2006). Portanto, é importante compreender as ideias básicas de interdisciplinaridade que orientam a elaboração de tais documentos oficiais.

A LDB (BRASIL, 1996) é um documento geral que propõe a criação de "áreas do conhecimento", o que poderia ser entendido como uma sugestão para que as disciplinas se fundissem, numa perspectiva interdisciplinar. No entanto, este documento não menciona explicitamente tal finalidade, e não se refere à interdisciplinaridade.

As orientações federais PCNEM (BRASIL, 1999) e PCN+ (BRASIL, 2002) sugerem que a base comum para o currículo escolar seja organizada em torno de três áreas de conhecimento: i) Linguagens, códigos e suas tecnologias; ii) Ciências Naturais, Matemática e suas tecnologias, e iii ) Ciências Humanas e suas tecnologias. Nesse contexto, a Química é alocada dentro de "Ciências Naturais, Matemática e suas tecnologias". Esta proposta de organização compreende grupos de disciplinas centradas em objetos de estudo que permitam ações interdisciplinares. Estes parâmetros enfatizam a organização do conhecimento em áreas, com o objetivo de contextualização e interdisciplinaridade. $\mathrm{O}$ fato dos Parâmetros Curriculares Nacionais estarem organizados em cada uma das áreas por disciplinas distintas, não significa que estas são obrigatórias, nem recomendadas. A divisão em áreas de conhecimento pode ser 
entendida como uma tentativa de incluir interdisciplinaridade na organização curricular brasileira, que é, em sua maior parte, disciplinar.

O documento PCNEM (BRASIL, 1999) pretende que no Ensino Médio, o aluno seja capaz de construir um pensamento estruturado, fazendo-se necessário repensar a organização curricular com relação ao modo como as diferentes disciplinas estão dispostas, pois os conteúdos separados permitem que o aluno compreenda apenas parte da situação ou do objeto em estudo. Dessa forma, é expresso no documento que uma maior compreensão decorre, quando relações entre conteúdos das diferentes disciplinas se estabelecem numa abordagem interdisciplinar. A interdisciplinaridade defendida pelo documento é assim apresentada:

\begin{abstract}
A interdisciplinaridade deve ir além da mera justaposição de disciplinas, e ao mesmo tempo, evitar a diluição delas em generalidades. De fato, será principalmente na possibilidade de relacionar as disciplinas em atividades, ou projetos de estudo, pesquisa e ação, que a interdisciplinaridade poderá ser uma prática pedagógica e didática adequada aos objetivos do Ensino Médio. O conceito de interdisciplinaridade fica mais claro quando se considera o fato trivial de que todo o conhecimento, que pode ser de questionamento, confirmação, de complementação, de negação, de ampliação, de iluminação de aspectos não distinguidos.

[...] A interdisciplinaridade também está envolvida quando os sujeitos que conhecem, ensinam e aprendem sentem necessidade de procedimentos que, numa única visão disciplinar, podem parecer heterodoxos, mas fazem sentido quando chamados a dar conta de temas complexos. (BRASIL, 1999, p. 132)
\end{abstract}

Essas interrelações “[...] entre as disciplinas tradicionais pode ir da simples comunicação de ideias até a integração mútua de conceitos, da epistemologia, da terminologia, da metodologia e dos procedimentos de coleta e análise de dados" (BRASIL, 1999, p. 88).

Observamos que a interdisciplinaridade deve ser compreendida, a partir de uma abordagem relacional em que se propõe que, por meio da prática escolar, ocorra estabelecimento de interconexões, integrando as disciplinas, criando condições favoráveis para uma aprendizagem motivadora, na medida em que se oferece maior incentivo aos educadores para desenvolverem conteúdos diretamente relacionados ao contexto social.

Especificamente em relação ao ensino de Química, o documento intenciona que o aluno do Ensino Médio compreenda as transformações químicas que ocorrem no mundo físico de forma integrada, pois o conhecimento químico isolado é importante, porém insuficiente para o entendimento desse mundo. Neste sentido, incentiva-se o estudo por temas que permitem uma contextualização dos conhecimentos. Essa inserção na realidade pode ser feita a partir da hidrosfera, litosfera e biosfera, permitindo uma 
interrelação com outras disciplinas, uma vez que esses assuntos: “[...] requerem não só o conhecimento específico, mas fundamentalmente o entendimento do resultado das interações entre os conhecimentos químicos e os conhecimentos físicos, biológicos e geológicos" (BRASIL, 1999, p. 247).

O documento PCNEM (BRASIL, 1999) defende ainda uma interação entre as disciplinas, mas preserva a sua identidade e especificidade. As disciplinas são convidadas a contribuir no sentido de aumentar a compreensão sobre o objeto de estudo. Com relação à abordagem interdisciplinar, observamos indícios de uma proposta em que o próprio sujeito faz o diálogo com as outras disciplinas, uma vez que o documento enfatiza a necessidade de relacionar conceitos para melhor compreensão do objeto de estudo e remete-se às ideias de estruturalismo psicogenético de Piaget.

Já os PCN+ (BRASIL, 2002), ao assumir que as disciplinas devem ser mobilizadas com a intenção de produzir um ensino relacionado com o universo vivencial do educando, sugere uma articulação desses saberes através de temas estruturadores, como: Universo, Terra, Vida, Biosfera, Transformações etc., pela facilidade que eles encontram de transitar por múltiplas disciplinas. A respeito de como essa articulação entre as áreas do conhecimento pode ser alcançada, o documento menciona que:

[...] a ideia de que a perspectiva interdisciplinar de conteúdos educacionais apresentados com o contexto no âmbito de uma ou mais áreas, não precisa necessariamente de uma reunião de disciplinas, pois pode ser realizada por uma única. (BRASIL, 2002, p.17, grifo nosso)

Essa intencionalidade pode ser observada, também no item que trata do propósito de cada disciplina. Em relação ao ensino de Química, traz especial atenção para as atividades experimentais, estudos do meio, diversificação de materiais ou recursos didáticos. É interessante verificar que o desenvolvimento de Temas Geradores, ou Projetos contemplam, se não todas, mas várias das estratégias sugeridas, segundo esse documento:

O desenvolvimento de projetos disciplinares, ou interdisciplinares, articulando todas essas formas de ação ou recursos pedagógicos, é extremamente propício para o desenvolvimento das diferentes competências almejadas, particularmente aquelas associadas à contextualização sóciocultural: selecionar um tema de relevância científica, tecnológica, social ou cultural associado ao conhecimento químico, programar suas diferentes etapas, dividir tarefas e responsabilidades no grupo, buscar e trocar informações prévias, desenvolver as ações previstas, avaliá-las e relatá-las, usando diferentes meios e instrumentos de comunicação, interagir com outras comunidades. (BRASIL, 2002, p.109) 
Dessa forma, o trabalho interdisciplinar sugere necessariamente um enraizamento no contexto, que pode ser explicado pela mobilização das disciplinas.

O PCN+ (BRASIL, 2002) aponta para a necessidade de articulação entre as áreas, em função do desenvolvimento de competências. Nota-se que o conteúdo, a interdisciplinaridade e a contextualização são mobilizados, com a finalidade de facilitar as interconexões entre as áreas. Outro ponto marcante neste documento é a menção explícita de que a interdisciplinaridade pode ser desenvolvida por um professor de uma única disciplina, ou seja, admite-se a possibilidade de algumas superações epistemológicas, onde o mesmo professor desenvolve conteúdos de outras disciplinas. Essa menção pode ser constatada na seção que trata dos "Conhecimentos, competências, disciplinas e seus temas estruturadores", sendo observada também nas áreas de Biologia e Química e inferida nas demais.

As OCNEM (BRASIL, 2004, 2006) expressam a necessidade de articular, integrar e sistematizar fenômenos e teorias em um campo científico, entre as diferentes áreas das ciências e do conhecimento. Esse documento enfatiza a necessidade de integração de diferentes áreas do conhecimento.

\footnotetext{
Construir uma visão sistematizada das diferentes linguagens e campos de estudo da Química, estabelecendo conexões entre diferentes temas e conteúdos.

Adquirir compreensão do mundo, da qual a Química é parte integrante, por meio dos problemas que ela consegue resolver e dos fenômenos que podem ser descritos por seus conceitos e modelos.

Articular o conhecimento químico e o de outras áreas no enfrentamento das situações-problema, como identificar e relacionar aspectos químicos, físicos e biológicos em estudos sobre a produção, destino e tratamento de lixo ou sobre a sua composição, poluição e tratamento das águas com aspectos sociais, econômicos e ambientais. (BRASIL, 2004, p. 237)
}

Segundo esse documento, os professores devem interagir com diferentes disciplinas, para tentar relacionar conceitos com outras disciplinas, assim construindo uma cultura científica geral. A abordagem interdisciplinar exige conhecimento específico, e é considerada na perspectiva dos professores.

Os professores devem necessariamente dialogar com as outras disciplinas, relacionar as nomenclaturas e os conceitos de que fazem uso, com o uso feito nas demais disciplinas, construindo com isso uma cultura científica mais ampla. Isso implica propiciar espaços de interação e condições de trabalho, resultando numa nova cultura escolar, mais verdadeira, ampla e significativa: 


\begin{abstract}
A interdisciplinaridade supõe um projeto político-pedagógico de escola bem articulado com a parceria dos gestores, sendo essencial estabelecerem relações que envolvam saberes diversificados, os dos alunos e os das disciplinas, não como mera justaposição, propiciando um conhecimento do fenômeno na sua complexidade. Reafirma-se que, no âmbito da escola, é necessário proporcionar tempo para encontros sistemáticos de professores por áreas de estudo, que contribuam para avaliar ações disciplinares e interdisciplinares, bem como para projetar novas ações, o que potencializa práticas de trabalho coletivo sobre contextos vivenciais, ou temas sociais. Sem os encontros periódicos, tais práticas tendem a permanecer como episódios isolados, sem romper com a fragmentação e a linearidade da organização curricular (BRASIL, 2006, p. 133, grifo nosso)
\end{abstract}

A interdisciplinaridade necessita do conhecimento específico dos participantes. Neste sentido, ela é pensada na perspectiva entre professores.

O documento OCNEM busca explicitar os avanços presentes na LDB, PCNEM e PCN+. Ao fazê-lo, aponta ações decisivas marcadas pela efetiva participação dos professores na definição teórico-metodológica de implementação curricular. Com relação à prática interdisciplinar, esta necessita da participação de cada uma das disciplinas pelos professores. A interdisciplinaridade é pensada na perspectiva entre professores, em que é incentivado o diálogo entre as disciplinas pelos participantes. Reafirma-se que a compreensão de reformas efetivas só acontece na viabilização real da articulação entre gestores, professores, estudantes e comunidades, em processos decisórios coletivos, que devem garantir autonomia e respeito à diversidade.

A Tabela 2 reúne as concepções de interdisciplinaridade prevalecentes nos documentos oficiais de ensino investigados, de acordo com as categorias propostas.

Tabela 2 - Concepções de Interdisciplinaridade identificadas nos documentos oficiais.

\begin{tabular}{c|c|c}
\hline Documentos oficiais & \multicolumn{2}{c}{$\begin{array}{c}\text { Concepções Epistemológicas de } \\
\text { Interdisciplinaridade }\end{array}$} \\
\hline & entre os professores & pelo professor \\
\hline $\begin{array}{c}\text { Lei de Diretrizes e Bases da Educação } \\
\text { Brasileira -LDB (BRASIL, 1996) }\end{array}$ & -- \\
\hline $\begin{array}{c}\text { Parâmetros Curriculares Nacionais do Ensino } \\
\text { Médio - PCNEM (BRASIL, 1999) }\end{array}$ & & $\mathrm{X}$ \\
\hline $\begin{array}{c}\text { Orientações complementares aos Parâmetros } \\
\text { Curriculares Nacionais - PCN+ (BRASIL, } \\
\text { 2002) }\end{array}$ & & $\mathrm{X}$ \\
\hline $\begin{array}{c}\text { Orientações Curriculares Nacionais do Ensino } \\
\text { Médio - OCNEM (BRASIL, 2004, 2006) }\end{array}$ & $\mathrm{X}$ & \\
\hline
\end{tabular}

É interessante notar que a análise revela que a interdisciplinaridade é retratada de acordo com abordagens distintas nos diferentes documentos educacionais. Embora os documentos PCNEM e PCN+ sugiram que o trabalho interdisciplinar pode ser realizado 
por cada professor, o documento OCNEM sugere uma abordagem diferente, em que a interdisciplinaridade deve ser perseguida por um grupo de professores. Tais discrepâncias epistemológicas podem ter implicações educacionais importantes na forma como a orientação oferecida pelo currículo prescrito realmente atinge as práticas de sala de aula, o que representa uma dificuldade significativa para a construção de propostas interdisciplinares. $\mathrm{Na}$ base de tais discrepâncias podem estar fatores essencialmente práticos que dificultam essa implementação como tempo, estrutura escolar e outros mais teóricos como a filosofia da escola.

\section{Interdisciplinaridade vista pelos pesquisadores e professores de química}

As concepções de interdisciplinaridade dos pesquisadores e professores de química do Ensino Médio foram avaliadas através de entrevistas (dezesseis no total), as quais foram analisadas por meio do uso de mapas cognitivos. A Figura 1 mostra o mapa do conceito que resultou a partir de uma entrevista do professor (P1).

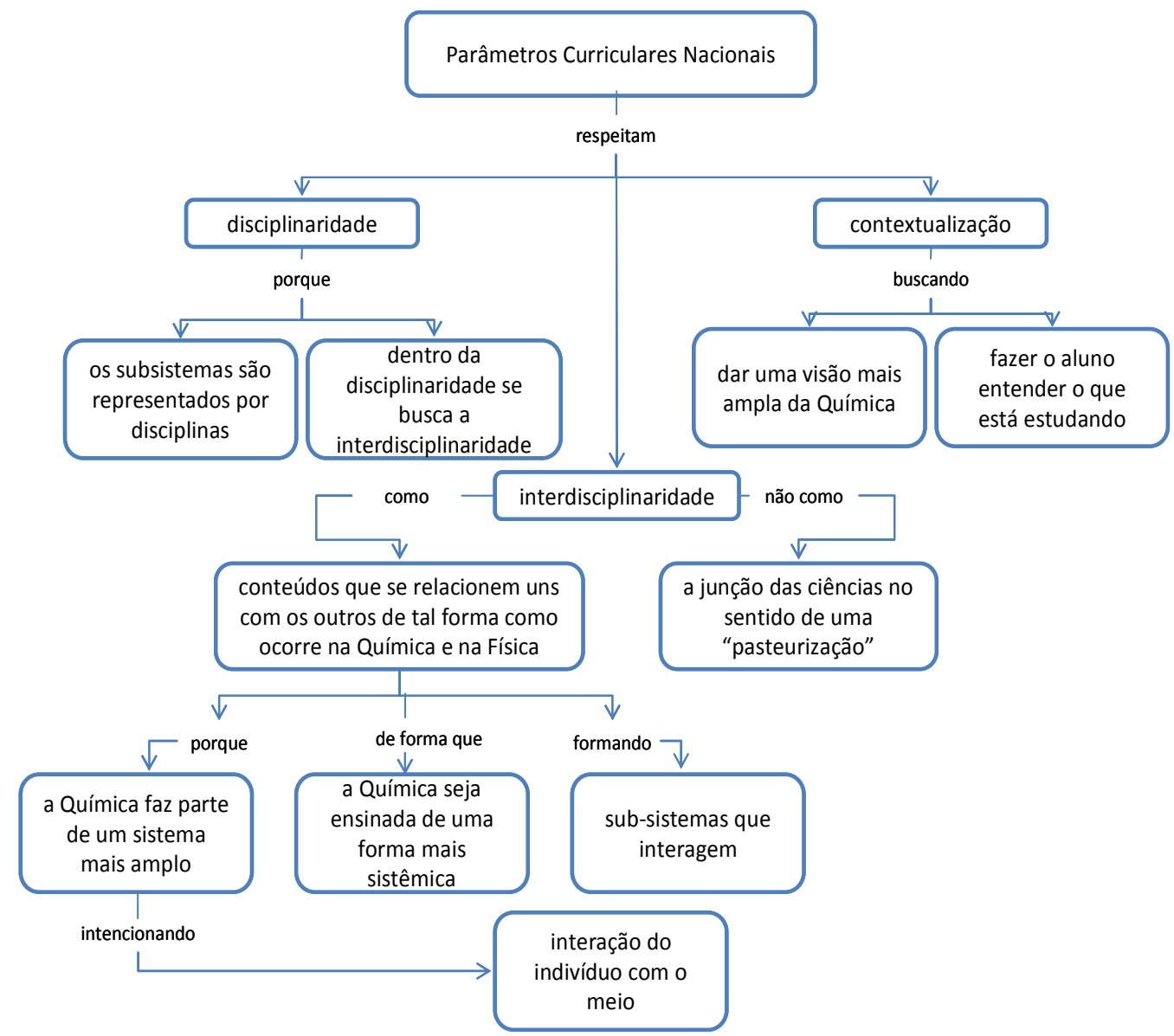

Figura 1 - Mapa cognitivo representando a interdisciplinaridade como expressa nos PCNEM de acordo com o professor-pesquisador de química entrevistado (P1). 
A Figura 1 apresenta a interpretação do professor sobre a concepção de interdisciplinaridade que aparece nos Parâmetros Curriculares Nacionais. Vale ressaltar que P1 foi consultor do MEC na elaboração desse documento. De acordo com a visão de P1, o PCNEM enfatiza a disciplinaridade, buscando uma relação entre as disciplinas através da interdisciplinaridade e considera, ao mesmo tempo, o contexto no qual a disciplina está inserida. A ideia seria mostrar que a química pertence a um sistema mais amplo, com conteúdos relacionados com a Física, por exemplo. Com relação às abordagens integradas, este professor-pesquisador aponta três modalidades de ensino: multidisciplinar, interdisciplinar e transdisciplinar (Figura 2).

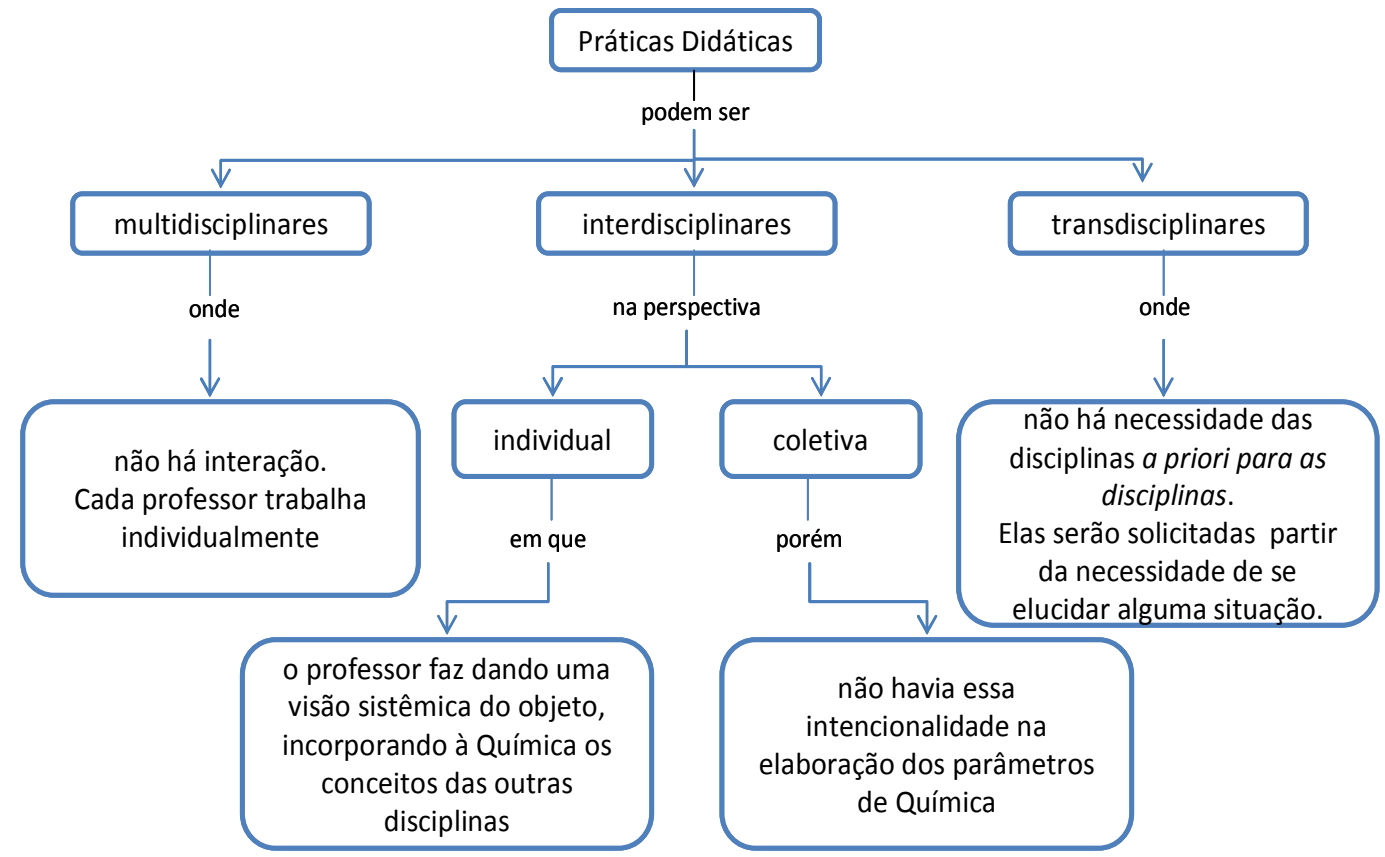

Figura 2 - Mapa cognitivo representando as práticas didáticas de acordo com o professor-pesquisador P1.

A Figura 2 apresenta uma concepção em que a interdisciplinaridade deve ser perseguida por cada professor (pelo professor), em relação a outros conteúdos disciplinares. A justificativa é a de gerar uma visão sistêmica do objeto estudado. No entanto, quando se refere à interdisciplinaridade entre os professores, este professor aponta o fato de que esta não foi a intenção na elaboração dos Parâmetros Curriculares Nacionais (PCNEM, 1999).

A Figura 3 apresenta um mapa cognitivo que descreve a educação básica como expressa nos documentos oficiais de ensino, de acordo com P2. De acordo com este mapa, no domínio da ciência, da matemática e suas tecnologias, enquanto a organização disciplinar é mantida, é encorajada a comunicação com outras disciplinas. Esse diálogo 
entre as disciplinas é necessário para evitar uma aprendizagem fragmentada (ver mapa cognitivo na Figura 4).

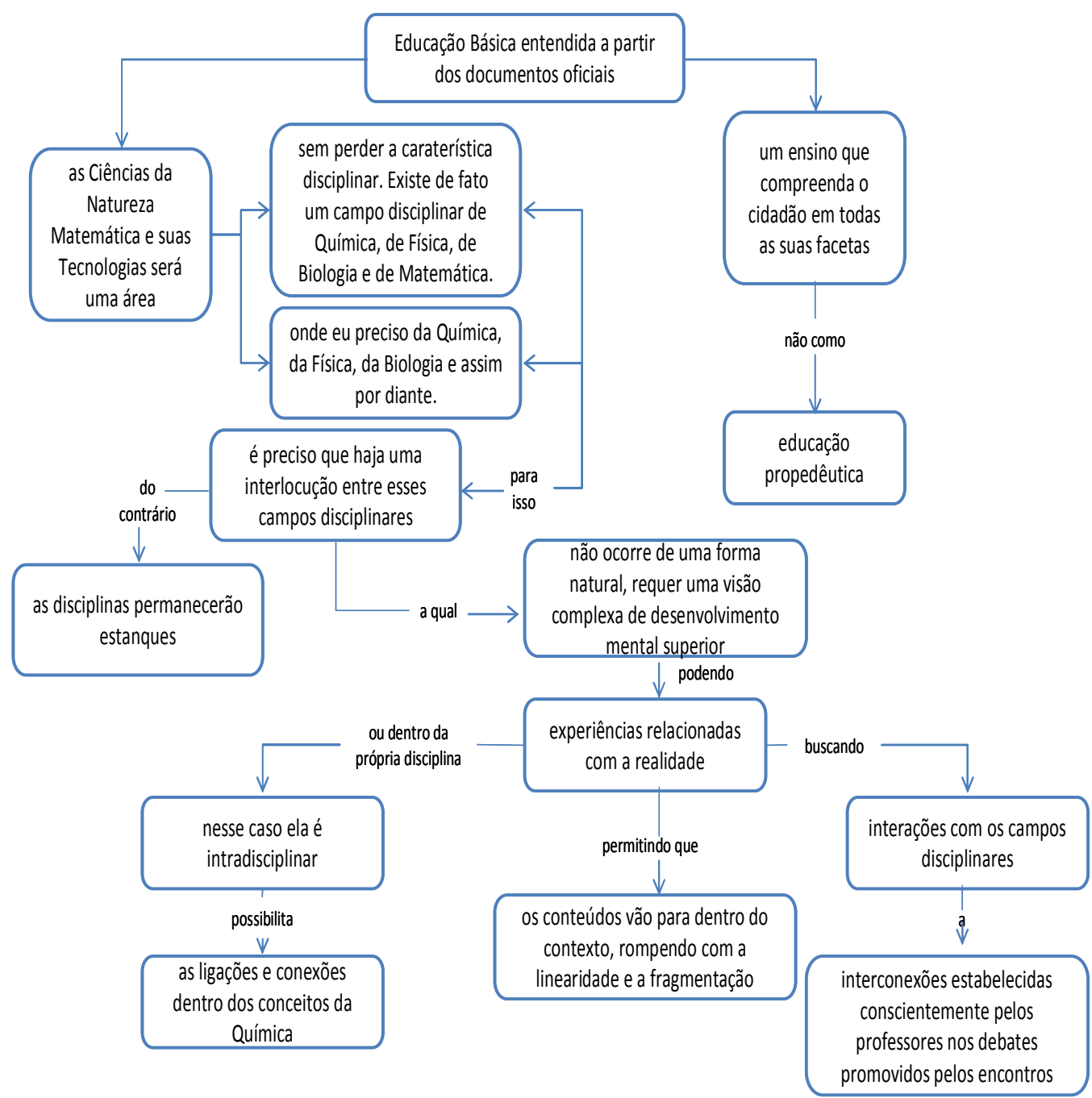

Figura 3 - Mapa cognitivo representando a educação básica segundo o professor-pesquisador P2.

A Figura 4 apresenta um mapa cognitivo que descreve a concepção de práticas didáticas para P2, e sugere a necessidade de um diálogo entre as disciplinas, a fim de evitar um processo de ensino fragmentado. Enquanto a interdisciplinaridade surge como colaboração entre as disciplinas, as fronteiras disciplinares são mantidas. Neste entendimento do professor, interdisciplinaridade é um esforço que tem de ser construído pelo grupo. Algumas superações podem ser alcançadas individualmente, que são, no entanto, limitadas pela formação disciplinar dos professores. 




Figura 4 - Mapa cognitivo representando as práticas didáticas de acordo com o professor-pesquisador P2.

Outro professor destaca que as práticas didáticas são partes do conhecimento total, e podem ser intradisciplinar, multidisciplinar, interdisciplinar e transdisciplinar (Figura 5). Na abordagem interdisciplinar, as conexões são criadas entre os conteúdos disciplinares. Essas conexões têm de ser feitas por cada indivíduo que precisa entender além de seu conteúdo específico. De acordo com este professor (P4), a interdisciplinaridade é um esforço que deve ser construído pelo professor. 


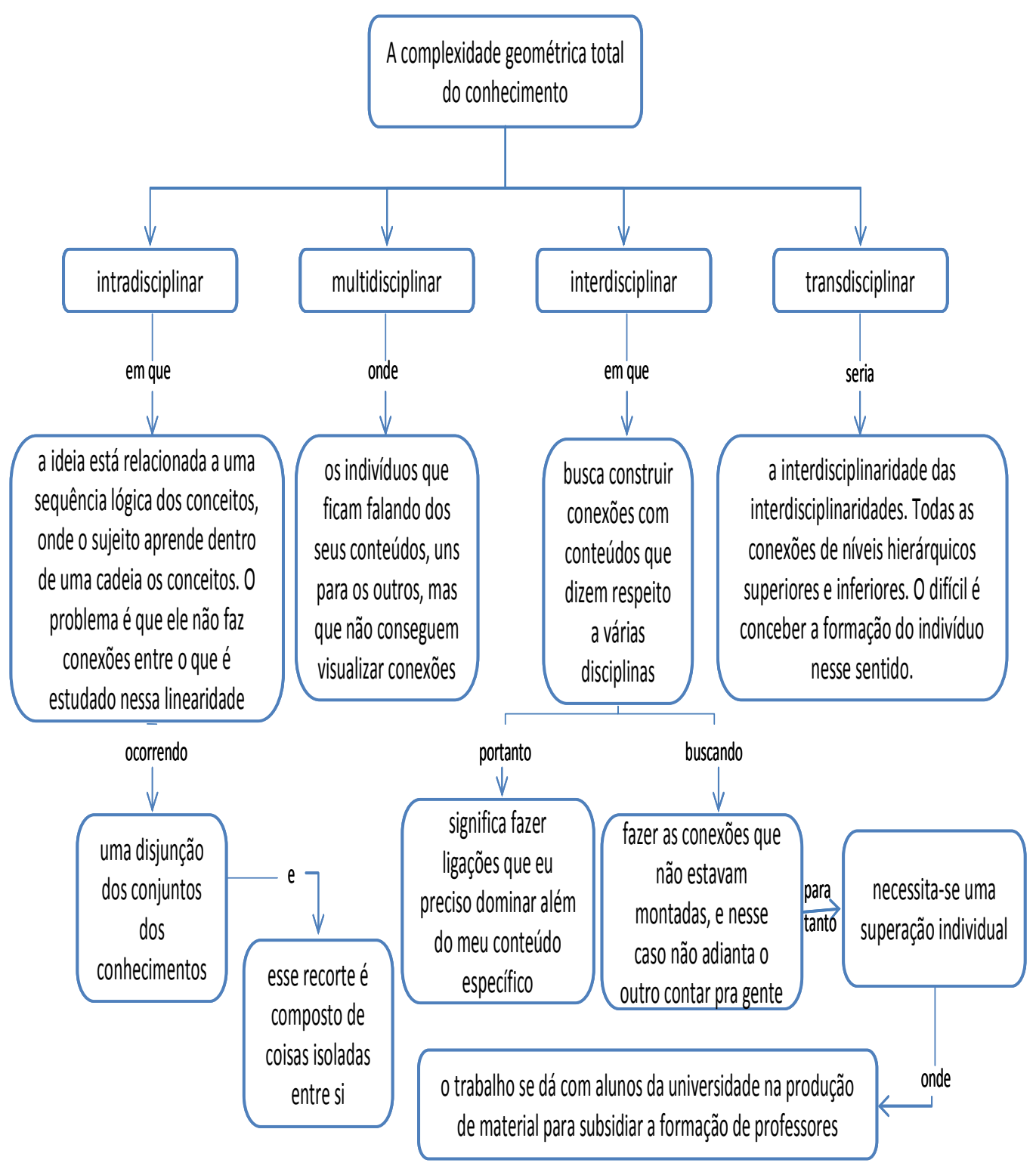

Figura 5 - Mapa cognitivo representando a interdisciplinaridade de acordo com professor-pesquisador P4.

Para o professor P11, o trabalho interdisciplinar não seria iniciado por um único professor. Interdisciplinaridade seria uma responsabilidade partilhada pelo conjunto de professores que trabalham em conjunto. Os professores devem se concentrar em um tema ou assunto que pode ser abordado por diferentes disciplinas (Figura 6). 


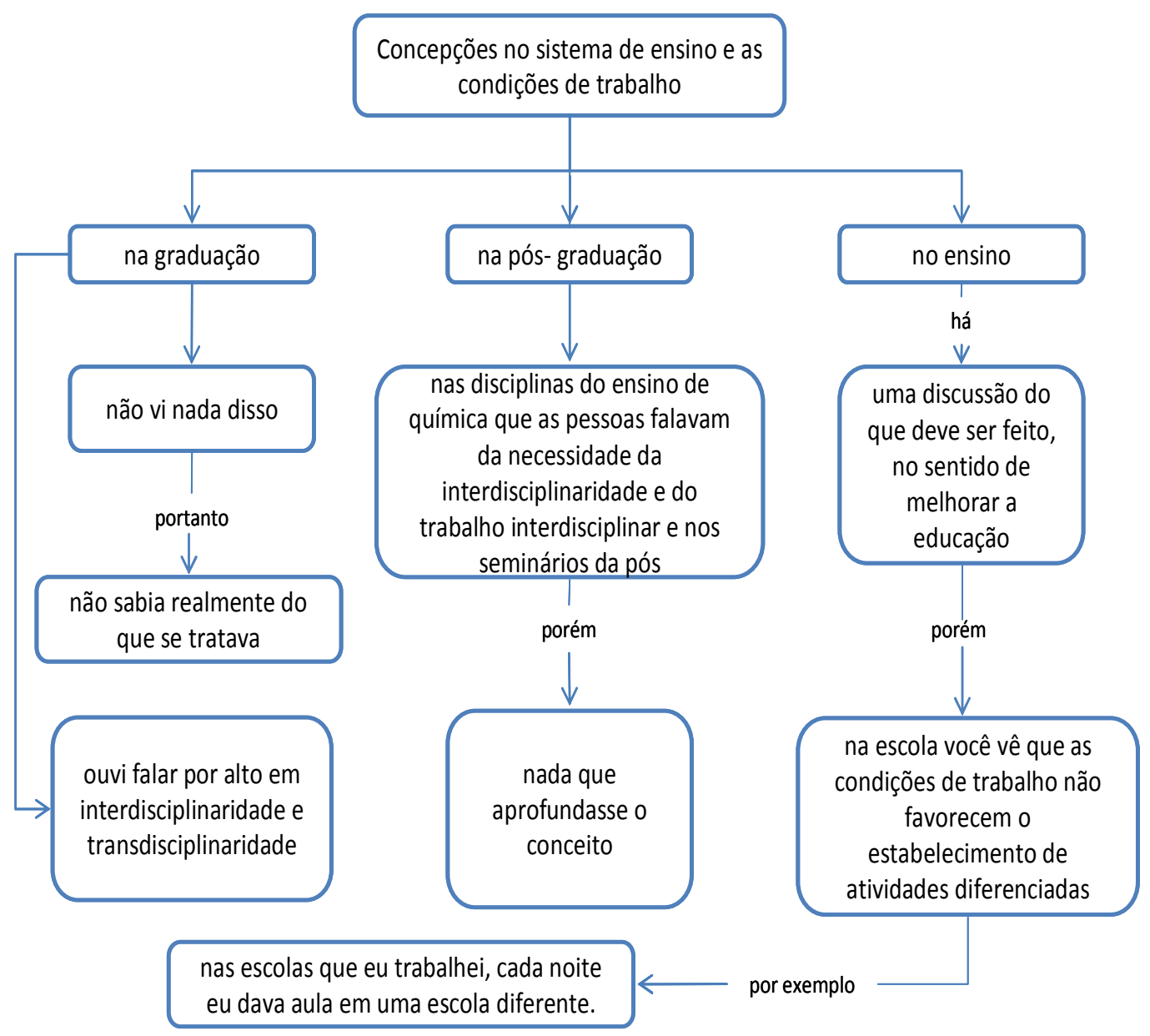

Figura 6 - Mapa cognitivo representando conceitos de interdisciplinaridade no sistema de ensino e as condições de trabalho de acordo com o professor entrevistado (P11).

P1, P3 e P4, acreditam que a interdisciplinaridade deva ser feita pelo próprio professor. Para P4:

[...] para me formar em física e em educação para fazer ensino de química, eu preciso fazer a conexão entre essas coisas que demanda tempo, muita leitura e muito estudo, estou tendo que ler duas áreas, tendo que fazer conexões que não estavam montadas, todos nós que vamos atuar nesta área temos que fazer essas conexões pessoalmente, não adianta o outro contar pra gente que fez, tenho que construir as minhas [...] (ENTREVISTA, P4).

P2 considera que,

[...] o melhor é você realmente criar grupos de professores que são inicialmente interdisciplinares [...] (ENTREVISTA, P2)

Já Para P6 o melhor seria:

[...] construir uma disciplinaridade que converse com as outras áreas, uma disciplinaridade que saiba reconhecer nela, os elementos das outras disciplinas, o que é muito difícil, porque nós não sabemos o que aparece na biologia, na química e nem na física. Isso é um desafio e certamente não é para o aluno, é para o professor [...] (ENTREVISTA, P6) 
No entendimento de P9 a interdisciplinaridade é um atributo da escola, e não do professor:

[...] fica parecendo que o professor de química sozinho tem que ser capaz de desenvolver em cima de um assunto só toda a interdisciplinaridade possível, ou seja, fazer uma abordagem biológica, social, física, histórica, geográfica, e que o assunto der abertura para ser feito. Eu acredito que isso não seria interdisciplinaridade, ela não seria exatamente isso, um único professor tendo o conhecimento de todas essas especificidades. (ENTREVISTA, P9)

Essas diferentes posturas também se revelam nos dados das entrevistas com os professores conforme pode ser visualizado na Tabela 3.

Tabela 3 - Concepções de Interdisciplinaridade identificadas nos professores entrevistados.

\begin{tabular}{|c|c|c|}
\hline \multirow[t]{2}{*}{ Professores entrevistados* } & \multicolumn{2}{|c|}{$\begin{array}{c}\text { Concepções Epistemológicas de } \\
\text { Interdisciplinaridade }\end{array}$} \\
\hline & entre os professores & pelo professor \\
\hline ( $\quad P 1$ & & $X$ \\
\hline P2 & $x$ & \\
\hline P3 & & $\mathrm{x}$ \\
\hline P4 & & $\mathrm{x}$ \\
\hline P5 & $X$ & \\
\hline P6 & $x$ & \\
\hline P7 & $x$ & \\
\hline P8 & $x$ & \\
\hline P9 & $x$ & \\
\hline P10 & $x$ & \\
\hline P11 & $x$ & \\
\hline P12 & $\mathrm{x}$ & \\
\hline P13 & $\mathrm{x}$ & \\
\hline P14 & $x$ & \\
\hline P15 & $x$ & \\
\hline ( $\quad$ P16 & $x$ & \\
\hline
\end{tabular}

* P1 a P8 professores/pesquisadores; P9 a P11 alunos da pós-graduação e P12 a P16 professores de Química do Ensino Médio.

A análise de dezesseis entrevistas de professores de química permitiu a categorização de seus pontos de vista sobre a interdisciplinaridade na categoria pelo professor para três deles (P1, P3 e P4). Todos os demais (P2 e P5 a P16) acreditam numa interdisciplinaridade feita entre um grupo de professores - entre os professores, concordantes assim com a postura defendida pelas OCNEM e divergentes da postura que aparece no PCNEM e PCN+.

Para os professores de Química do Ensino Médio em prática, o conceito de interdisciplinaridade entre os professores é altamente prevalente. 
Cabe ressaltar, entretanto, que tanto nos documentos como na fala dos professores e pesquisadores ( $\mathrm{P} 1$ a P16) fica evidente o consenso de que a interdisciplinaridade pressupõe a presença das disciplinas na escola.

\section{Conclusões}

$\mathrm{O}$ estudo aqui apresentado sugere que o conceito de interdisciplinaridade convive com pelo menos duas interpretações muito distintas epistemologicamente. Estas abordagens foram denominadas interdisciplinaridade pelo professor (considera que uma abordagem interdisciplinar deve ser desenvolvida por cada professor individualmente), admitindo a necessidade do conhecimento de conteúdo de disciplinas distintas e interdisciplinaridade entre professores (considera que uma abordagem interdisciplinar deve ser construída pelo trabalho conjunto de professores de disciplinas de origens distintas). Estas categorias se mostraram muito úteis na compreensão de como este conceito é concebido.

O caráter dual do termo interdisciplinaridade foi verificado na literatura, nos documentos oficiais de ensino brasileiros e nos professores atuantes na escola básica e na universidade.

Esta investigação mostra que a concepção pelo professor se relaciona com as proposições de Piaget, Jantasch, Bianchetti, Bertalanffy e com os documentos Parâmetros Curriculares Nacionais do Ensino Médio (PCNEM e PCN+). Entre os professores entrevistados, apenas três concordavam com este ponto de vista.

Por outro lado, a ideia de interdisciplinaridade entre os professores é expressa pelos autores Gusdorf, Japiassu, Santomé, Fazenda, Machado e Zabala, e é também expressa pelos documentos Orientações Curriculares Nacionais para o Ensino Médio (2004 e 2006).

Para os professores do Ensino Médio em serviço o conceito de interdisciplinaridade entre professores parece prevalecer. Esses professores entrevistados expressaram dificuldades conceituais significativas no entendimento sobre a interdisciplinaridade e como o trabalho interdisciplinar pode ser realizado.

A preferência pela interdisciplinaridade entre professores parece explicitar uma dificuldade dos professores em realizar a interdisciplinaridade sozinho em sua sala de aula, além de revelar uma visão equivocada de interdisciplinaridade, talvez sendo confundida com multidisciplinaridade em que um mesmo tema é tratado por diversos professores sob o ângulo de sua disciplina e de forma tradicional. Nossos dados 
reforçam assim a ideia apontada por Augusto et al. (2004) em que os professores são unânimes em valorizar a interdisciplinaridade, julgam-na importante, mas que na prática não conseguem se distanciar da multidisciplinaridade.

Este trabalho de pesquisa aponta que a interdisciplinaridade coexiste com concepções diferentes: na literatura, nos professores pesquisadores de ensino de química, de ensino de física e de educação, consultores, nos documentos orientadores e nos professores de química do Ensino Médio.

Fica clara a prevalência da concepção de interdiscipinaridade entre professores na literatura, nos documentos oficiais e nos professores de ensino de química e física e de educação investigados, vários dos quais elaboradores dos mesmos documentos oficiais analisados. Essa prevalência, contudo, pode estar mascarando uma falta de entendimento epistemológico dessa concepção e revelando um entendimento equivocado da prática interdisciplinar entre professores com a prática multidisciplinar já conhecida. De qualquer forma, para ambas há necessidade de condições estruturais na escola, de espaços e tempos para discussão entre os pares e de uma incorporação da interdisciplinaridade na formação dos professores de química. Tais dificuldades necessitam ser consideradas pelos agentes públicos antes que mudanças curriculares mais profundas sejam implementadas.

\section{Agradecimentos}

Os autores agradecem aos professores participantes da pesquisa e o apoio financeiro para o grupo de pesquisa conduzido por agências governamentais brasileiras CNPq, CAPES e FAPESP (Processo N. 13/07937-8). Agradecem ainda à Secretaria da Educação do Estado de São Paulo pela bolsa concedida para esta investigação.

\section{Referências}

ARAÚJO F. T.; RIEDG, D. L. Mapas Cognitivos como ferramenta de estruturação e resolução de problemas: o caso da pró-reitoria de extensão da UFSCar. Gestão e Produção, v.10, n.2, p.145-165, 2003.

AUGUSTO, T.G.S.; CALDEIRA, A. M.A.; CALUZI, J.J.; NARDI, R. Interdisciplinaridade: concepções de professores da área ciências da natureza em formação em serviço. Ciência \& Educação, v.10, n.2, p. 277-289, 2004.

BARDIN, L. Análise de conteúdo. Lisboa: Edições 70, 2003. 
BERMEJO, M. L.; GONZÁLEZ, T.; MELLADO, V. Cognitive Maps for Interviews as a Procedure to Analyze Science Teachers' Conceptions of the Nature of Science. In: CAÑAS, A.. J.; NOVAK, J. D.; GONZÁLEZ, F. M. (Eds.) Concept Maps: Theory, Methodology, Technology. Proceedings of the First International Conference on Concept Mapping, Pamplona, Spain, 2004. p.1-4.

BERTAlANFFY, L. von. Teoria geral dos Sistemas. 3. ed. Petrópolis, RJ: Editora Vozes, 1977.

BERTALANFFY, L. von ¿Que es la Teoría General de Sistemas?, 2012. Disponível em http://www.portalga.ea.ufrgs.br/ Acesso em 17/Jun/ 2014.

BERTI, V.P. Interdisciplinaridade: um conceito polissêmico. Dissertação de Mestrado em Ensino de Ciências, Universidade de São Paulo, 2007.

BRASIL. Ministério da Educação. Lei de Diretrizes e Bases da Educação Nacional: Lei 9.394/96, 1996.

Ministério da Educação - Secretaria de Educação Média e Tecnológica. Parâmetros Curriculares Nacionais: Ensino Médio. Brasília, 1999.

Ministério da Educação. Secretaria de Educação Média e Tecnológica PCN+ Ensino Médio: Orientações educacionais complementares aos Parâmetros Curriculares Nacionais, 2002.

- Ministério da Educação. Secretaria de Educação Média e Tecnológica Orientações Curriculares para o Ensino Médio, Brasília, 2004.

- Ministério da Educação. Secretaria de Educação Média e Tecnológica Orientações Curriculares para o Ensino Médio, Brasília, 2006.

COLL, R.K.; GILBERT, J.K.; PILOT, A.; STRELLER, S. How to benefit from the informal and interdisciplinary dimension of chemistry in teaching. In: EILKS, I; HOFSTEIN, A. (Eds.) Teaching Chemistry - a Studybook. Practical Guide and Textbook for student teachers, teacher trainees and teachers. Roterdam: Sense Publishers, 2013. p.241-268.

CZERNIAK, C.M. Interdisciplinary Science Teaching. In: ABELL, S.; LEDERMAN, N.G. (Eds.) Handbook of Research in Science Education. New York: Routledge, 2007. p.537-559.

EDEN, C. Cognitive Mapping. European Journal of Operational Research, v.36, p.1$13,1988$.

FAZENDA, I. C. A. Didática e Interdisciplinaridade. 9 ed. Campinas, São Paulo: Editora Papirus, 2005.

Interdisciplinaridade: História, teoria e pesquisa. Campinas, São Paulo: Editora Papirus, 1994. 
Editora Cortez, 1993.

(Org.). Práticas interdisciplinares na escola. 2 ed. São Paulo:

GUSDORF, G. Conhecimento interdisciplinar. In: OLGA, P. (Org.). Interdisciplinaridade Antologia. 1 ed. Lisboa: Editora Campo das Letras, 2006.

Para uma pesquisa interdisciplinar. In: Diógenes: Antologia. Brasília: Editora da UnB, v.7. p.35, 1984.

JANTASCH, A. P.; BIANCHETTI, L. (Org.). Interdisciplinaridade: para além da filosofia do sujeito. Petrópolis: Editora Vozes, 1995.

JAPIASSU, H. Interdisciplinaridade e Patologia do Saber. Rio de Janeiro: Editora Imago, 1976.

LLINARES, S. Los mapas cognitivos como instrumento para investigar las creencias epistemológicas de los profesores. In: GARCIA, C. M. La investigación sobre la formación del profesorado. Métodos de investigación y análisis de dados. Buenos Aires: Cincel, 1992. p.57-95.

LOPES, A.C. Currículo e epistemologia. Rio Grande do Sul: Editora. Editora UNJUÍ, 2007.

LOPES, A.C.; MACEDO, E. (Orgs.). Disciplinas e integração curricular: história e políticas. Rio de Janeiro: Editora DP\&A, 2002.

MACHADO, N. J. Epistemologia e didática: as concepções de conhecimento $e$ inteligência e a prática docente. $5^{\mathrm{a}}$ ed. São Paulo: Editora Cortez, 2002.

Educação: projetos e valores. São Paulo: Editora Escrituras, 2001.

MELlADO, V.; SILVA, C.; RUIZ, C. Los Mapas Cognitivos, Elaborados a partir del Cuestinario Inpecip (1993-2002) de las concepciones de una profesora de ciencias de secundaria. In: A. J. Cañas, J. D. Novak, F. M. González (Eds.) Concept Maps: Theory, Methodology, Technology. Proceedings of the First International Conference on Concept Mapping, Pamplona, Spain, 2004. p.1-8.

MELlADO, V.; SILVA, C.; RUIZ, C. Construcción de mapas cognitivos a partir del cuestionario INPECIP. Aplicación al estudio de la evolución de las concepciones de una profesora de secundaria entre 1993 y 2002. Revista Electrónica de Enseñanza de las Ciencias v.4, n.1, p.1-21, 2005.

MOZENA, E. R.; OSTERMANN, F. Integração curricular por áreas com extinção das disciplinas no Ensino Médio: Uma preocupante realidade não respaldada pela pesquisa em ensino de física. Revista Brasileira de Ensino de Física, v.36, n.1, p. 1403-1408, 2014.

PIAGET, J. Metodologia das relações interdisciplinares. In: Pombo, O.; Guimarães, H.; Levy, T. (Org.) Interdisciplinaridade. Antologia. 1 ed. Porto: Editora Campos das Letras, 2006. 
Para onde vai a educação? 6 ed. Rio de Janeiro: Livraria José Olimpio.

1978.

RICARDO, E. C.; ZYLBERSTAJN, A. Os Parâmetros Curriculares Nacionais para as Ciências do Ensino Médio: uma análise a partir da visão de seus elaboradores. Investigações em Ensino de Ciências, v.13, n.3, p .257-274, 2008.

RUIZ, C; SILVA, C; PORLÁN, R; MELLADO, V. Construcción de Mapas Cognitivos a partir del Cuestinario Inpecip. Revista Electrónica de Enseñanza de las Ciencias. v.4, n.1, p.1-21, 2005.

SANTOMÉ, J. T. Globalização e interdisciplinaridade: o currículo integrado. Porto Alegre: Editora Artes Médicas Sul Ltda, 1998.

ZABALA, A. Enfoque Globalizador e pensamento complexo: uma proposta para o currículo escolar. Porto Alegre: Editora Artmed, 2002.

A prática educativa: como ensinar. Porto Alegre: Editora Artmed, 1998.

VALDIR PEDRO BERTI. Possui graduação em Ciências Licenciatura e no Ensino de Química (1990), mestrado em Ensino de Ciências- modalidade Química pela Universidade de São Paulo (2007). É professor efetivo do Estado de São Paulo desde 1989 e, desde 2003 atua como PCNP no Ensino de Química, trabalhando com formação de professores de química e ciências para a rede estadual e municipal. É professor das Faculdades FACCAT na graduação e pós-graduação, desde 2008. Atuou como tutor de professores de Química do Estado de São Paulo (2010) pela FUNDAP/SEE/SP. Participou, ainda, na validação da matriz de referência para o SARESP, modalidade Química (2008) e da reelaboração e revisão dos Cadernos do Aluno e do Professor de Química da SEE/SP (2014-2017).

CARMEN FERNANDEZ. Possui graduação em Bacharel em Química com atribuições tecnológicas (1985), graduação em Licenciatura em Química (2001), mestrado em Química (1991), e doutorado em Química (1996), todos pela Universidade de São Paulo, Brasil. Realizou um estágio de pós-doutoramento na Universidade da California - Berkeley e no Lawrence Berkeley National Laboratory (1996-1999). Atuou como professora de Química no Ensino Médio em várias escolas de São Paulo. Desde 2003 é docente no Departamento de Química Fundamental do Instituto de Química da Universidade de São Paulo. Desde 2014 é professora associada nesse mesmo departamento. Coordena o grupo PEQuim - Pesquisa em Ensino de Química que tem por interesse de pesquisa principal o Professor de Química, e atua principalmente nas seguintes linhas de pesquisa: conhecimento de professores de Química, conhecimento pedagógico de conteúdo, base de conhecimentos para o ensino, desenvolvimento profissional e formação de professores de Química. Foi avaliadora para o MEC de livros de química e de Ciências do Programa Nacional de Livros Didáticos, tem vários artigos e capítulos de livros publicados na área de ensino de química tanto nacionais como internacionais. É membro do corpo editorial do periódico Journal of Science Education. Atua como revisora de diversos periódicos da área de Ensino de Química e 
como revisora de projetos de fomento do CNPq, CAPES, FAPESP e FAPEMIG. É pesquisadora bolsista de produtividade nível 2 do CNPq.

Recebido: 28 de julho de 2014

Revisado: 15 de janeiro de 2015

Revisado: 29 de janeiro de 2015

Aceito: 10 de fevereiro de 2015 